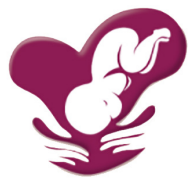

Published By : PERINASIA The Indonesian Society of Perinatology

\title{
Methylglyoxals, Thiocyanate, and Hydrogen Peroxide in saliva of newborns at risk of sepsis: Methylglyoxals as a promising biomarker of early-onset neonatal sepsis
}

\author{
Ari Yunanto ${ }^{1 *}$, Pricilia Gunawan $\mathrm{H}^{1}$, Eko Suhartono ${ }^{2}$
}

${ }^{1}$ Neonatology Division of Child Health Department, Ulin General Hospital/Faculty of Medicine Universitas Lambung Mangkurat, Banjarmasin, Indonesia ${ }^{2}$ Department of Biochemistry, Faculty of Medicine Universitas Lambung Mangkurat, Banjarmasin, Indonesia

*Corresponding to: Ari Yunanto; Neonatology Division of Child Health Department, Ulin General Hospital/Faculty of Medicine Universitas Lambung Mangkurat, Banjarmasin, Indonesia; ariefkaunlam@gmail.com

Received: 2020-10-15 Accepted: 2021-01-20 Published: 2021-02-26
ABSTRACT

Introduction: Sepsis represents a severe problem for newborns. The relatively high incidence rate of 1 to 10 cases per 1000 live births, with even higher rates in low-birth-weight neonates. Given its high incidence, identifying markers to optimize the early diagnosis and therapeutic interventions is highly desirable. This study investigates three oxidative markers taken from saliva, methylglyoxal (MG), Thiocyanate $\left(\mathrm{SCN}^{-}\right)$and hydrogen peroxide $\left(\mathrm{H}_{2} \mathrm{O}_{2}\right)$, as early-onset neonatal sepsis markers. Methods: This study was conducted from June to August 2014, and saliva specimens were taken from 30 newborns of mothers with one major risk factor or two minor risk factors (case group) and 30 healthy newborns for the control group. Saliva levels of $\mathrm{MG}$ were determined by calculating the percentage of MG absorbance compared with the carbonyl compounds. Data were analyzed by using Kolmogorov-Smirnov and Student's t test.

Results: We found a significant increase of $\mathrm{SCN}$, and MG level case group (28.91 mmol and $0.01 \%$, respectively) compared to the control group ( $19.49 \mathrm{mmol}$ and $0.005 \%$, respectively) $\mathrm{p}$-value $=0.03$. In contrast, the $\mathrm{H}_{2} \mathrm{O}_{2}$ in the case group ( $32.56 \mathrm{mmol}$ ) was lower than the control group $(37.47 \mathrm{mmol})$, with a $\mathrm{p}$-value $=0.04$.

Conclusion: We found the increased levels of $\mathrm{SCN}^{-}, \mathrm{MG}$ and the decreased levels of $\mathrm{H} 2 \mathrm{O} 2$ in neonates' saliva with the risk of sepsis. MG measurements as a routine diagnostic for suspected sepsis should be taken into consideration.

Keywords: methylglyoxal, Thiocyanate, hydrogen peroxide, early-onset neonatal sepsis.

Cite This Article: Yunanto, A., Gunawan, H.P., Suhartono, E. 2021. Methylglyoxals, Thiocyanate, and Hydrogen Peroxide in saliva of newborns at risk of sepsis: Methylglyoxals as a promising biomarker of early-onset neonatal sepsis. Indonesian Society Of Perinatology 2(1): 1-5. DOI: 10.51559/inajperinatol.v2i1.6

\section{INTRODUCTION}

Neonatal sepsis or septicemia is clinical syndromes during the first month of life caused by systemic responses to infection and supported by discovering microorganisms in the blood cultures. ${ }^{1}$ Sepsis is a leading cause of neonatal mortality, especially in developing countries. It is estimated that mortality caused by sepsis is about $30-50 \%$ of all neonatal deaths. ${ }^{2}$ Indonesian perinatal mortality data reported that $29.9 \%$ of deaths occurred on the first day of life and $75.6 \%$ at one week after birth. ${ }^{3}$ Babies who are born with risk factors have a greater possibility to have sepsis. ${ }^{1}$ In terms of sepsis timing, early neonatal sepsis occurs within the first three days of life. ${ }^{2}$ Several obstetric and neonatal factors have been associated with an increased risk of neonatal infection. The presence of any of those factors alone is not an indication for a complete sepsis workup or antibiotic therapy. Nonetheless, the presence of a set of risk factors should significantly enhance the suspicion of neonatal sepsis. ${ }^{4}$

Various pathomechanisms have been proposed in neonatal sepsis. Oxidative stress due to the general inflammatory response has been pointed as the seed for sepsis development. ${ }^{5}$ Oxidative stress is mediated by several enzymatic reactions, originally intended to establish a defense system against microbial invasion. ${ }^{6}$ This enzymatic defense is orchestrated by endogenous enzymes through the various scavenging reactions of reactive oxygen species (ROS) and nitrogen metabolites derived from polymorphonuclear neutrophils (PMN), the well-known process called the respiratory burst. ${ }^{6,7}$
Hydrogen peroxide $\left(\mathrm{H}_{2} \mathrm{O}_{2}\right)$ as the latter product during respiratory burst will be transformed into antimicrobial compounds by peroxidase enzymes found in blood and saliva. ${ }^{8-10}$ Peroxidase catalyzes the oxidation of halide and pseudohalide ions such as iodide $\left(\mathrm{I}^{-}\right)$, bromide $\left(\mathrm{Br}^{-}\right)$, chloride $\left(\mathrm{Cl}^{-}\right)$and thiocyanate $\left(\mathrm{SCN}^{-}\right)$as its cosubstrate in the presence of $\mathrm{H}_{2} \mathrm{O}_{2}$, leading to the production of a much more bactericidal and fungicidal agent. ${ }^{9,11} \mathrm{SCN}^{-}$ is the primary substrate for lactoperoxidase (LPO), and the closely related salivary peroxidase (SPO), the preferred substrate for myeloperoxidase (MPO). ${ }^{12}$

Although clinical reports are consistent with ROS involvement in neonatal sepsis and its complications, strangely, not much conclusive evidence supports the beneficial effect of antioxidants treatment in sepsis., ${ }^{5,13}$ It may indicate that other 
mediators of cellular stress, such as reactive carbonyl species (RCS), play a much larger role. Research has shown that various, heterogeneous groups of RCS emerged as essential mediators of cellular dysfunction. These compounds are relatively stable and quickly diffuse out of the cell. Thus, these molecules can exert an Effect far from the formation site. Like many other oxidants, several of the most potent RCS is derived from the glycolysis process. ${ }^{14,15}$ Among many, Methylglyoxal (MG) is a highly reactive electrophilic $\quad \alpha, \beta$-dicarbonyl aldehyde compound, one of several compounds of the RCS group, produced endogenously during glycolysis. ${ }^{16-18}$

During sepsis, glycolytic contribution to energy production increases about $10 \%$ as a compensatory mechanism to sustain the energy supply. ${ }^{19}$ Glycolytic enhancements might be related to or stimulated by mediators produced during the systemic inflammatory response..$^{20}$ The Glycolysis inevitably produces methylglyoxals (MGs) as a by-product, and the rate of formation is correlated with the rate of glycolysis. In advance, MG is a pro-oxidant and an AGEs precursor. ${ }^{15,21}$ MG also induces hydrogen peroxide production in neutrophils and platelets. ${ }^{22}$

From those pathological conditions, it can be assumed that the energy generation pathways, inflammatory, and oxidative processes have such relationships. However, there has been no research that relates these forms of metabolic stress in neonatal sepsis. Therefore, this study aimed to measure $\mathrm{MGs}, \mathrm{SCN}^{-}$, and $\mathrm{H}_{2} \mathrm{O}_{2}$ level in the saliva of newborns at risk of sepsis, the main objective was to investigate the used of MG as biomarkers in neonates with septicemia risk which, can be used as an early marker for earlyonset neonatal sepsis.

\section{METHODS}

This study is a prospective cross-sectional study approved by the Research Ethics Committee Faculty of Medicine Lambung Mangkurat University / Ulin General Hospital (No.012/KEPK-FK UNLAM/ EC/IV2015). Saliva specimens were taken from 30 newborns at risk of sepsis and 30 healthy newborns (control group) in which their parents had signed the informed consent. The study was conducted from
June to August 2014 at the Neonatology Division of Ulin General Hospital Banjarmasin. Samples were examined in the Biochemistry Laboratory at the Faculty of Medicine Lambung Mangkurat University, Banjarmasin. The inclusion criteria were newborns from mothers with a major risk factor or two minor risk factors. Major risk factors were rupture of membranes $>24$ hours, intrapartum fever $\left(>38{ }^{\circ} \mathrm{C}\right)$, chorioamnionitis, a persistent fetal heart rate $>160$ beats/minute, and foul-smelling amniotic fluid. Minor risk factors were rupture of membrane $>12$ hours, intrapartum fever $\left(>37.5{ }^{\circ} \mathrm{C}\right)$, low Apgar score $\left(<5\right.$ at the $1^{\text {st }}$ minute, $<7$ at $5^{\text {th }}$ minute), very low birth weight babies $(<1500$ grams), gestational age $<37$ weeks, multiple pregnancies, foul-smelling vaginal discharge, maternal urinary tract infection (UTI) / suspected untreated UTI. Exclusion criteria are babies born outside Ulin General Hospital Banjarmasin, newborns with severe asphyxia, newborns with major congenital abnormalities, low birth weight $(<2500$ grams).

\section{Protein Carbonyl Assay}

The modified dinitro-phenylhydrazine (DNPH) method was used to measure the Carbonyl compounds. From each test solution, a $0.5 \mathrm{ml}$ solution was. It was divided into two tubes, $0.25 \mathrm{ml}$ in volume in each tube. The two tubes are a sample tube (A) and a blank/non-sample tube (B). Each of the sample tubes (tube A) was given a drop of $1 \mathrm{ml}$ of DNPH, and each blank tube (tube B) were $1 \mathrm{ml}$ $\mathrm{HCl} 2.5 \mathrm{M}$. All the tubes were incubated for 45 minutes at room temperature and protected from light, then shaken with vortex for 15 minutes. A milliliter of trichloroacetic acid (TCA) 20\% was added into each tube (A and $\mathrm{B}$ ) and then incubated for another 5 minutes. Tubes were recentrifuged $(1400 \mathrm{rpm})$ for about 5 minutes to separate the supernatant. The pellets were further centrifuged and washed three times with the addition of 1 $\mathrm{ml}$ ethanol-ethyl acetate mixture. The final step was to measure carbonyl compounds by adding $1 \mathrm{ml}$ of urea $(9 \mathrm{M})$ and then incubated and shaken for 10 minutes at 37 oC. The solutions were centrifuged again for 5 minutes at $1400 \mathrm{rpm}$. The absorbance of the solution was measured at $\lambda=390$ nm. Protein breakdown was measured by using the following formula.
(A : absorbance,

$$
\mathrm{C}=\mathrm{A} /(\mathrm{e} . \mathrm{b})
$$
e : extinction coefficient $22000 \mathrm{mMcm}^{-1}$, $\mathrm{b}: 1 \mathrm{~cm})$

\section{Methylglyoxal (MGs) Assay and measurement}

A total of $25 \mu \mathrm{L}$ of the homogenate was added to $350 \mu \mathrm{L}$ DNPH $(0.1 \% \mathrm{DNPH}$ in $2 \mathrm{~N} \mathrm{HCl}$ ), and then $2.125 \mathrm{ml}$ distilled water was added. It is incubated for 15 minutes at $37^{\circ} \mathrm{C}$, then $1.5 \mathrm{ml} \mathrm{NaOH} 10 \%$. Absorbance was measured at $\lambda=576 \mathrm{~nm} .{ }^{23}$ MGs level was determined by calculating the percentage of MGs absorbance compared with the carbonyl compounds. The formula to determine the MGs level is presented below.

$$
\text { MGs level (\%) }=\frac{\text { MGs absorbance }}{\text { Carbonyl absorbance }} \times 100 \%
$$

\section{Hydrogen Peroxide Assay}

Five milliliters of phosphate buffer $(\mathrm{pH} 7$ and concentration of $0.01 \mathrm{M}$ ) was mixed with $1 \mathrm{~mL}$ of saliva and was homogenized slowly. A milliliter of the mixture was taken and was mixed with $2 \mathrm{~mL}$ dichromat/glacial acetate. It was heated for 10 minutes in boiling water to remove the blue precipitate and produce a green solution. The absorbance was measured at $\lambda=570 \mathrm{~nm}$. A Standart curve was used to determine how much of the remaining $\mathrm{H}_{2} \mathrm{O}_{2}$ when the reaction was stopped by acetic acid.

\section{Thiocyanate Assay}

Standart solutions contain $800 \mu \mathrm{l} \mathrm{HCl}$ $0,1 \mathrm{~N}$ was mixed with $100 \mu \mathrm{FeCl}_{3} 0,1 \mathrm{M}$ and $100 \mu \mathrm{KSCN} 0,1 \mathrm{M}$. The mixture was centrifuged at $1000 \mathrm{rpm}$ for 10 minutes. Absorbance was measured at $\lambda=450$ $\mathrm{nm}\left(\mathrm{A}_{\mathrm{o}}\right)$. Samples solution contain $800 \mu \mathrm{l}$ $\mathrm{HCl} 0,1 \mathrm{~N}$ was mixed with $100 \mu \mathrm{FeCl}_{3}$ $0,1 \mathrm{M}$ and $100 \mu \mathrm{l}$ saliva. The mixture was centrifuged at $1000 \mathrm{rpm}$ for 1 minute. Absorbance was measured at $\lambda=450 \mathrm{~nm}$ $\left(A_{1}\right)$. The following formula measured thiocyanate level (C1) in saliva:

$$
\mathrm{C}_{1}=\frac{\mathrm{A} 1 \times \mathrm{Co}}{\mathrm{Ao}}
$$




\section{Statistical Methods}

Data from both groups were analyzed statistically for comparation. The normal distribution of the variables was tested with the Kolmogorov-Smirnov test. The mean comparison of the control group variables with the case group was analyzed with Student's $t$ test (if the requirement was met, otherwise the equivalent nonparametric test was used). P-values of 0.05 or less were considered statistically significant.

\section{RESULTS}

Subjects' characteristics in both groups were presented in Table 1. Risk factors of 30 subjects in the case group were presented in Table 2. Each subject may have more than one risk factor.

Overall, there were significant differences between the mean of the variables measured in the newborn at risk of sepsis (case group) and the control group. We found mean Thiocyanate (SCN) level in the control group is $19.49 \mathrm{mmol}$, and in the case group mean $\mathrm{SCN}^{-}$level is $28.91 \mathrm{mmol}$. It showed that the $\mathrm{SCN}^{-}$ level in the case group was higher than the control. From Kolmogorov Smirnov, data have normal and homogeneous distribution. To assess the difference between both groups, data were analyzed using an independent t-test, and the result showed a significant difference between the groups $(\mathrm{p}=0.03)$. In contrast, the mean $\mathrm{H}_{2} \mathrm{O}_{2}$ level in the control group was higher $(37.47 \mathrm{mmol})$ than in the case group $(32.56 \mathrm{mmol})$. From the KolmogorovSmirnov test, the data was known to have normal distribution. The statistical test results using independent $t$-test showed a significant difference between the groups $(\mathrm{p}=0.04)$. Lastly, the mean MG level in the control group is lower $(0.005 \%)$ than in the case group $(0.01 \%)$. From the Kolmogorov-Smirnov test, data have normal and homogeneous distribution. The independent $\mathrm{t}$-test showed that there is a significant difference between the

\section{Table 1. Characteristics of subjects}

\begin{tabular}{lcc}
\hline \multicolumn{1}{c}{ Characteristic } & Control group $(\mathbf{n}=\mathbf{3 0})$ & Case group $(\mathbf{n}=\mathbf{3 0})$ \\
\hline Sex & 11 & 12 \\
$\quad$ Male & 19 & 18 \\
$\quad$ Female & & \\
Delivery & 15 & 16 \\
$\quad$ Spontaneous delivery & 2 & 3 \\
Breech extraction & 12 & 10 \\
Caesarian section & 1 & 1 \\
Vacuum extraction & & \\
\hline
\end{tabular}

Table 2. Risk factors of subjects

\begin{tabular}{lc}
\hline \multicolumn{1}{c}{ Risk factors } & $\mathbf{n}$ \\
\hline Membranes ruptured for $>24$ hours & 9 \\
Membranes ruptured for $>24$ hours \& Foul-smelling vaginal discharge & 5 \\
Foul-smelling vaginal discharge \& Maternal UTI or suspected untreated maternal & 5 \\
UTI & 4 \\
Membranes ruptured for $>12$ hours \& Maternal fever with intrapartum & \\
temperature $>38.5^{\circ} \mathrm{C}$ & 3 \\
Foul-smelling vaginal discharge \& Gestational age $<37$ weeks & 2 \\
Membranes ruptured for $>24$ hours \& Gestational age $<37$ weeks & 2 \\
\hline
\end{tabular}

groups $(p=0.03)$. The mean level of SCN, $\mathrm{H}_{2} \mathrm{O}_{2}$ and $\mathrm{MG}$ in both groups is presented in Figure 1.

\section{DISCUSSION}

The saliva defense mechanism is the first line against harmful microorganisms. ${ }^{7,9}$ Saliva defense system inhibits microorganisms through various in vivo activity of salivary antimicrobials. ${ }^{25}$ One of those salivary microbial is an enzymatic defense mechanism which is played by the respiratory burst. ${ }^{6,7}$ From this study, there was a significant difference between thiocyanate $\left(\mathrm{SCN}^{-}\right)$level between the groups where the saliva of neonates at risk of sepsis has higher levels of SCNWe also found decreased levels of $\mathrm{H}_{2} \mathrm{O}_{2}$ in the saliva of neonates with the risk of sepsis. This result indicates increased respiratory burst activity in the saliva of neonates with the risk of sepsis. High levels of Thiocyanate are required to activate LPO and MPO during sepsis. Under physiological condition, biological fluids such as saliva, breastmilk and tears only contain millimolar levels of $\mathrm{SCN}^{-25}$ The levels of $\mathrm{H}_{2} \mathrm{O}_{2}$ was found lower in case groups. The capitalization of $\mathrm{H} 2 \mathrm{O} 2$ causes it into antimicrobial end products.

Respiratory burst produced by the antimicrobial system through ROS formation, which catalyzed by NADPHoxidase. This reaction produced a suproxide radical that was then further modified to $\mathrm{H}_{2} \mathrm{O}_{2}$ and hydroxyl radicals $(\mathrm{OH})$ by superoxide dismutase (SOD). $\mathrm{H}_{2} \mathrm{O}_{2}$ will then be transformed into antimicrobial compounds by peroxidase enzymes in saliva. The lactoperoxidase (LPO) and myeloperoxidase (MPO) are the two principal components of the peroxidase system in saliva and work together to catalyze the oxidation of thiocyanate ions $\left(\mathrm{SCN}^{-}\right)$by $\mathrm{H}_{2} \mathrm{O}_{2}{ }^{8,9}$ The resulting product of the reaction is the more potent bactericidal and fungicidal compound such as $\mathrm{OSCN}^{-}$, HOSCN, $\mathrm{O}_{2} \mathrm{SCN}^{-}$, and $\mathrm{O}_{3} \mathrm{SCN}^{-}{ }^{-10,25,26}$ Salivary LPO$\mathrm{SCN}-\mathrm{H}_{2} \mathrm{O}_{2}$ has been proven to produce a positive unidirectional antimicrobial system through the various antibacterial mechanism of action. ${ }^{6,9-11}$

Another finding in this study was the difference in MG level between the control and case groups. MG levels were found 


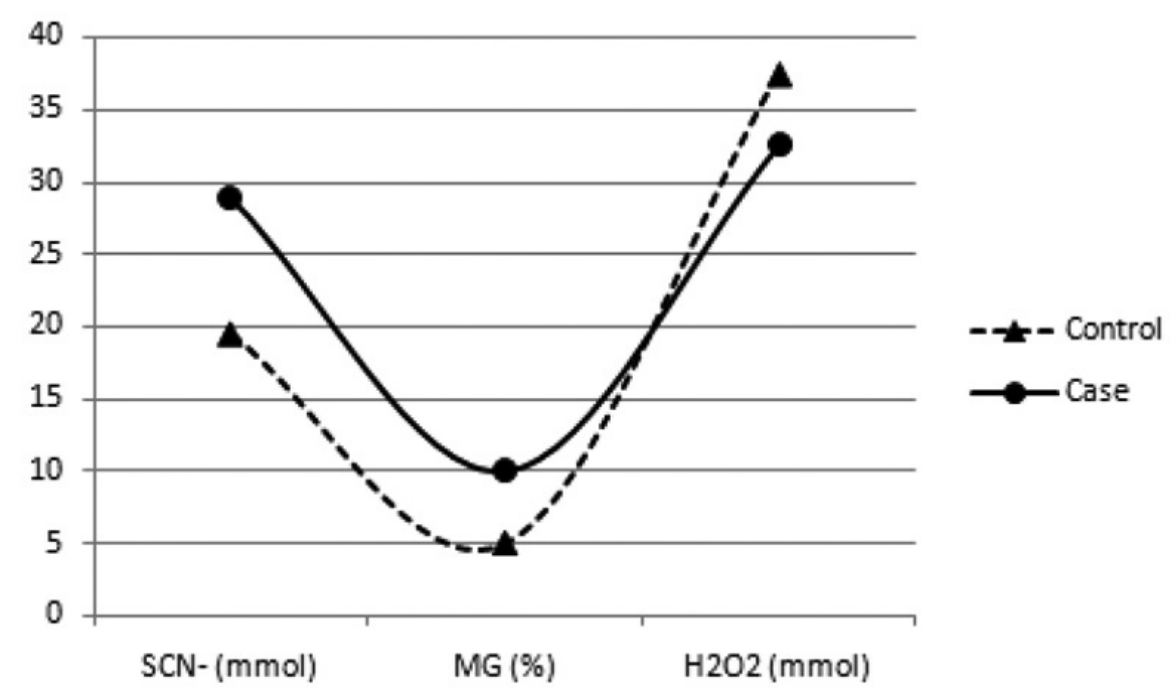

Figure 1. Mean levels of $\mathrm{SCN}^{-}, \mathrm{H}_{2} \mathrm{O}_{2}$ and $\mathrm{MG}$ in control and case group

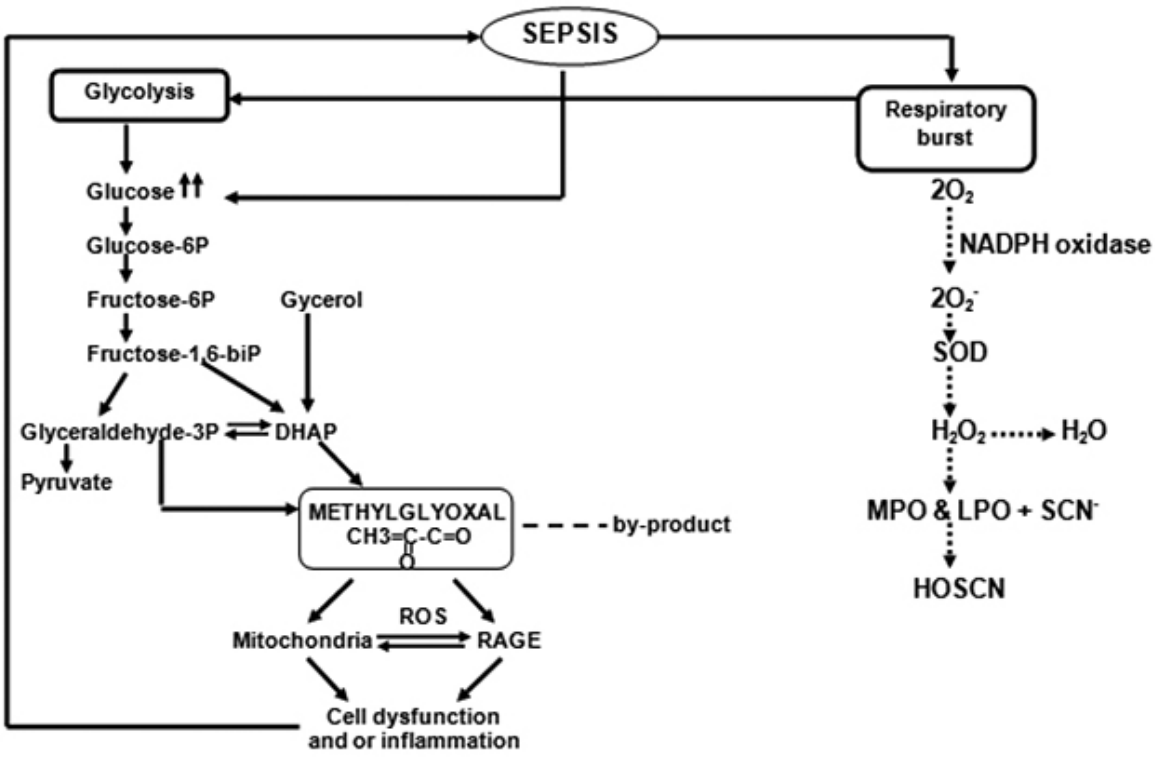

Figure 2. Respiratory burst, glycolysis and formation of MG in sepsis, novel approach of MG as a neonatal sepsis marker. ${ }^{15,28,29,34,36}$

higher in the saliva of newborns at risk of sepsis. In sepsis, inflammatory cytokines induced glucose uptake and glycolytic flux in activated macrophages directed towards supplying ATP for respiratory burst. ${ }^{19}$ It was due to the dependency of neutrophils on glycolysis rather than oxidative metabolism for ATP generation to maintain the NADPH oxidase-driven respiratory burst required for killing certain bacteria. ${ }^{28}$ This finding suggests that the increased respiratory burst activity in neonatal sepsis leads to increased glycolytic flux as the cellular energy source for respiratory burst against microbial.
The rate of glucose uptake and glycolysis were thought to be influenced positively by mediators produced during the systemic inflammatory response in sepsis. ${ }^{20}$ Furthermore, it is also believed that any metabolic pathways that stimulate glycolytic activity may also increase the formation of MG, including the glycolysis pathway under physiological conditions and the activated polyolfructose pathway during the hyperglycemic conditions. The latter metabolic activity is one of the clinical features in patients with sepsis. ${ }^{29}$ As the glucose metabolism happens, MG is formed in a significant amount (approximately $0.1 \%$ of glucose flux) as a normal by-product resulted from the fragmentation of the triosephosphate glyceraldehyde-3-phosphate (GAP) and dihydroxyacetone phosphate (DHAP). ${ }^{21}$ These MG then underwent various reactions, as it readily reacts with lipids, nucleic acids, lysine and arginine residues of proteins to form AGEs with downstream inflammatory effects. ${ }^{17,30-32}$ Direct changes in protein function due to MG modification triggers an inflammatory response at the cellular level. ${ }^{33}$ In sepsis, modification of different proteins by MG, particularly in mitochondria, increased the oxidative load, further aggravating cellular dysfunction and inflammation. ${ }^{15,34}$ Oxidative modifications of proteins are more stable than lipids, making proteins suitable for oxidative stress markers. ${ }^{35}$ The schematic metabolism and mechanism of respiratory burst, MG, and MGderived AGEs driven cell dysfunction or inflammation or both in human sepsis is presented in Figure 2. Due to these biochemical characteristics, MG is believed to be a potential reliable marker in neonatal sepsis. Studies showed that MG is a better biomarker to predict survival in patients with septic shock than the routine and established biomarkers like C-reactive protein (CRP), procalcitonin (PCT), IL-6, and $\mathrm{SCD} 14-\mathrm{ST} .{ }^{15,36}$

\section{CONCLUSION}

In this study, we found the increased levels of $\mathrm{SCN}^{-}, \mathrm{MG}$ and the decreased levels of $\mathrm{H}_{2} \mathrm{O}_{2}$ in neonates' saliva with the risk of sepsis. Increased $\mathrm{SCN}^{-}$and MG levels followed by a decreased level of $\mathrm{H} 2 \mathrm{O} 2$ in this study suggest that MG 
metabolism is an important and generally overlooked biochemical pathway related to oxidative stress in early-onset neonatal sepsis pathomechanism. It also suggests that there is a relationship between these two forms of metabolic stress marker. ${ }^{15}$ Therefore, MG measurements in routine diagnostics of neonates with suspected sepsis should be taken into consideration. Further investigations are required to determine whether MG's diagnostic and prognostic value can be confirmed and validated to be used clinically.

\section{ACKNOWLEDGEMENT}

We thank all technicians in Biochemistry Laboratory at Faculty of Medicine of Lambung Mangkurat University for helping with this experiment.

\section{FUNDING}

No additional funding or third-party financial support had contributed to this study.

\section{CONFLICT OF INTEREST}

All authors declare no conflict of interest

\section{AUTHOR CONTRIBUTION}

All authors have contributed substantially during all phases of the study, including drafting and revising the manuscript, giving final approval, and agreeing to be accountable.

\section{REFERENCES}

1. Gardner SL. Sepsis in the neonate. Crit Care Nurs Clin N Am. 2009;21:121-41.

2. Simonsen KAAnderson-Berry AL, Delair SF, Daviesa H. Early onset neonatal sepsis. Clin Microbiol Rev. 2014;27:21-47.

3. Titaley CR, Dibley MJ, Agho K, Roberts CL, Hall J. Determinants of mortality in Indonesia. BMC Public Health. 2008;8:232.

4. Shaha CK, Dey SK, Shabu KH, Chisti J, Mannan MA, Jashimuddin MD, et al. Neonatal Sepsis-A Review. Bangladesh J Child Health. 2012;36:829.

5. Rocha M, R. Herance, S. Rovira, Antonio HM,Víctor MV. Mitochondrial dysfunction and antioxidant therapy in sepsis. Infect. Disord. Drug Targets. 2012;12:161-178.
6. Battino M, Ferreiro MS, Gallardo I, Newman HN, Bullon P. The antioxidant capacity of saliva. J Clin Periodontol.2002;29:189-194.

7. Reddy YN, Murthy SV, D.R. Krishna. Oxidative metabolic changes in pleural fluid of tuberculosis patients. Bangladesh J Pharmacol. 2009;4:69-72.

8. Yunanto A, Firdaus RT, Triawanti, Suhartono E. Advance oxidation protein products (AOPPs) of newborn at risk of sepsis as novel parameter for early-onset neonatal sepsis. IJBB. 2014;4:903.

9. Ihalin R, Vuokko L, Tenovuo J. Origin, structure, and biological activities of peroxidases in human saliva. Arch Biochem Biophys. 2006;445:261-8.

10. Nobuhiro G, Kuniaki T, Yuuko H, Harada $\mathrm{H}$, Ikari A, Tershima Y, et al. Effect of psychologic stress on peroxidase and thiocyanate level in human saliva detected by ultraweak chemiluminescence. J of Health Science.2007;53:161-9.

11. Welk A, Meller CH, Schubert R, Schwahn Ch, Kramer A, Below H. Effect of lactoperoxidase on the antimicrobial effectiveness of the thiocyanate hydrogen peroxide combination in a quantitative suspension test. BMC Microbiology. 2009;9:134.

12. Van Dalen CJ, Whitehouse MW, Winterbourn CC, Kettle AJ. Thiocyanate and chloride as competing substrates for myeloperoxidase. Biochem. J. 1997;327:487-92.

13. Galley HF. Oxidative stress and mitochondrial dysfunction in sepsis. Br J Anaesth. 2011;107:5764.

14. O'Brien PJ, Arno GS, Nandita S. Aldehyde sources, metabolism, molecular toxicity mechanisms, and possible effects on human health. Crit Rev Toxicol. 2005;35:609-62.

15. Brenner T, Thomas F, Florian U, Stephan S, Felix S, Eduardo S, et al. Methylglyoxal as a new biomarker in patients with septic shock: an observational clinical study. Crit Care. 2014; 18:683-93

16. Rabbani N, Thornalley PJ: Methylglyoxal, glyoxalase 1 and the dicarbonyl proteome. Amino Acids. 2012;42:1133-42.

17. Desai KM, Wu L. Methylglyoxal and advanced glycation end products: new therapeutic horizons? Recent Pat Cardiovasc Drug Discov. 2007;2:89-99.

18. Kalapos MP. The tandem of free radicals and methylglyoxal. Chem Biol Interact. 2008;171: 251-71.

19. Garcia-Alvarez M, Marik P, Bellomo R. Sepsis-associated hyperlactatemia. Crit Care. 2014;18:503-14

20. L'Her E, Sebert P. A Global approach to energy metabolism in an experimental model of sepsis. Am J Respir Crit Care. 2001;164:1444-7.

21. Allaman I, Bélanger $M$, Magistretti PJ. Methylglyoxal,the dark side of glycolysis. Front Neurosci. 2015;9:1-12.

22. Ward RA, McLeish KR. Methylglyoxal : a stimulus to a neutrophil radical production in chronic renal failure? Nephrol Dial Transplant. 2004;19:1702-7.

23. Leoncini G, Poggi M. Effects of methylglyoxal on platelet hydrogen peroxide accumulation, aggregation and release reaction. Cell Biochem Funct.1996;1:89-95.

24. Seo K, Ki SH, Shin SM. Methylglyoxal induces mitochondrial dysfunction and cell death in liver. Toxicol Res. 2014;30:193-8.

25. Tenovuo J. Antimicrobial agents in saliva : protection for the whole body. J Dent Res 2002;81:807-9.

26. Hawkins CL. The role of hypothiocyanous acid (HOSCN) in biological systems. Free Radic Res. 2009;43:1147-58.

27. Ashby MT. Inorganic chemistry of defensive peroxidases in the human oral cavity. J Dent Res. 2008;87:900-14.

28. McGovern NN, Cowburn AS, Porter L, Walmsley SR, Summers C, Thompson AAR, et al. Hypoxia selectively inhibits respiratory burst activity and killing of staphylococcus aureus in human neutrophils. J Immunol. 2011;186:45363.

29. Desai KM, Chang T, Wang H, Banigesh A, Dhar A, Liu J, et al. Oxidative stress and aging: Is methylglyoxal the hidden enemy? Can J Physiol Pharmacol. 2010;88:273-84.

30. Srikanth V, Westcott B, Forbes J, Phan TG, Beare R, Venn A, et al. Methylglyoxal, cognitive function and cerebral atrophy in older people. J Gerontol A Biol Sci Med Sci. 2013;68:68-73.

31. Mostafa AA, Randell EW, Vasdev SC, Gill VD, Han Y, Gadag V, et al. Plasma protein advanced glycation end products, carboxymethyl cysteine, and carboxyethyl cysteine, are elevated and related to nephropathy in patients with diabetes. Mol Cell Biochem. 2007;302:35-42.

32. Watanabe K, Okada K, Fukabori R, Hayashi $\mathrm{Y}$, Asahi K, Terawaki H, et al. Methylglyoxal (MG) and cerebro-renal interaction: does longterm orally administered MG cause cognitive impairment in normal sprague-dawley rats? Toxins. 2014;6:254-69.

33. Rabbani N, Thornalley PJ. Dicarbonyls linked to damage in the powerhouse: glycation of mitochondrial proteins and oxidative stress. Biochem Soc Trans. 2008;36:1045-50.

34. Buhimschi CS, Bhandari V, Han YW, Dulay AT, Baumbusch MA, Madri JA, et al. Using proteomics in perinatal and neonatal sepsis: hope and challenges for the future. Curr Opin Infect. 2009;22:235-43.

35. Veyseller B, F. Aksoy, B. Ertas, M. Keskin, O. Ozhuran, Y. S.Yilldirum, et al. A new oxidative stress marker in patients with nasal polyposis: advance oxidation protein products (AOPP). B-ENT. 2010;6:105-9.

36. Klebanoff SJ. Myeloperoxidase: friend and foe. J Leukoc Biol. 2005;77:598-625.

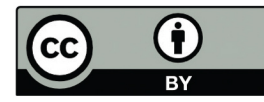

This work is licensed under a Creative Commons Attribution 